\title{
ADVANCING E-HEALTH IN SAUDI ARABIA: CALLING FOR SMART VILLAGE INITIATIVES
}

\author{
HASSAN TAIBAH ${ }^{1}$, SUDHA ARLIKATTI ${ }^{2}$ \& BILL DELGROSSO ${ }^{2}$ \\ ${ }^{1}$ King Abdulaziz University, Jeddah, Saudi Arabia \\ ${ }^{2}$ Rabdan Academy, Abu Dhabi, United Arab Emirates
}

\begin{abstract}
The Kingdom of Saudi Arabia (KSA) presents a unique case study for examining e-health initiatives as it is a country that has transformed itself from a predominantly rural population to an urban, developed one, within a short span of 65 years following the discovery of large oil reserves. This paper examines the tenets of the KSA's eHealth Program, the progress made, and the gaps identified in meeting the needs of KSA's rural populations. It begins with a brief review of e-health efforts in rural and urban settings around the world, followed by a concept map created from the Atlas of eHealth Country Profiles by the World Health Organization, to identify strengths and weaknesses across eight themes, within the participating countries. This is followed by a description of the KSA case study; and an analysis of advancements made and challenges faced, including e-health foundations, legal frameworks, electronic health records adoption, mobile health data access and social media use. Finally, we make suggestions regarding enhancement of rural health coverage through the creation of Smart Village initiatives in dispersed Saudi villages.
\end{abstract}

Keywords: e-health, eHealth Program, health communication, information technology, public health, rural populations, Saudi Arabia, Smart Village, World Health Organization.

\section{INTRODUCTION}

The World Health Organization (WHO), in a bid to ensure universal health coverage, is a proponent of e-health strategies. WHO defines e-health as "the use of digital information electronically transmitted, stored, or obtained, in support of healthcare, both at local and distance level" [1]. It uses an information and communication technology (ICT) infrastructure, health-related information and ICT users as the three elements of a system that collectively support easy access to and sharing of real-time and stored healthcare information and services; for clinical, academic and managerial purposes [2].

In the context of receiving healthcare, rural populations are often faced with inequitable health quality and accessibility issues; due to a lack of trained doctors, clinicians and infrastructure. This intensifies the burden of disease management and medical expenses [3]. Furthermore, complications arise from patients' inability to travel long distances [4], as specialized health care facilities are only available in distant urban centers. Rural residents may also face financial, social or cultural restrictions; and geographical barriers, making them less adept at accessing healthcare [5]. Thus, there is a need to design smart e-health village enterprises aimed at addressing the urban-rural divide, by making resources available remotely, in order to empower local self-governance that supports universal health coverage.

The term "Smart Village" includes the use of technology for development, enhancement of overall health and welfare, and to aid public education, interaction and engagement [6]. Malche and Maheshwary [7] also reinforced the value of information technology for providing better access to services, including smart healthcare as part of Smart Village initiatives. However, it is important that such technologies supplement existing care and gradually move towards substituting different care services; based on individuals' characteristics, environment and preferences [4], to counter scepticism and low adoption. 
This paper uses a case study approach and describes the context in the Kingdom of Saudi Arabia (KSA) and its eHealth Program, as well as progress to date. It proposes that in advancing e-health adoption in the country, attention should be directed to the needs of the KSA rural populations, as well. This country's case study is unique, because KSA has transformed itself from a predominantly rural population to an urban one, a developing nation to a developed one, within a short span of 65 years, following the discovery of large oil reserves. The United Nations (UN) Human Development Index (HDI) places Saudi Arabia in the "very high" category for human development, as it ranks 39th out of 189 countries [8]. Still, $17 \%$ of the KSA population remains rural, receiving scant attention at the national level for health care planning and program deliverables. This gap needs to be addressed, as over 2,000 villages are dispersed over a vast land area of 2.15 million $\mathrm{km}^{2}$ [9], making it difficult to provide timely, equitable, high-quality healthcare through traditional means.

The lack of clinicians to manage the increase in chronic diseases, such as diabetes, hypertension and heart diseases [10]; and contagious diseases, like Zika, MERS-Corona. and the Novel Corona Virus 2019 (COVID19), poses additional challenges.

This paper begins with a brief review of e-health efforts in rural and urban settings around the world, followed by a concept map created from the Atlas of eHealth Country Profiles by the WHO, to identify any strengths and weaknesses, across eight themes, in participating countries. This is followed by a description of the KSA case study; and an analysis of the advancements made, challenges faced and discussions of possible future strategies to reduce the urban-rural divide in adopting e-health. The paper concludes with suggestions for future research, including investments in creating Smart Village initiatives.

\section{LITERATURE REVIEW}

\subsection{International efforts in e-health adoption in both rural and urban areas}

A review of both rural and urban contexts around the world suggests that there are barriers to advancing e-health, depending on country-specific e-health policies, the availability of resources, funding, etc. E-health ICT applications are often viewed as instruments that help minimize the differences in providing healthcare services between rural and urban areas.

Ruxwana et al. [11] found that the factors influencing the adoption of e-health in the rural Eastern Cape provinces of South Africa included: inadequate infrastructure, services and resources; compounded by lower literacy rates, compared to other parts of the country. Additionally, public health authorities faced challenges from a lack of standardization and integration, poor technological resources, and a lack of ICT adoption or skills. They concluded that a successful implementation of e-health services requires three levels of resource commitments, namely: access to ICTs, access to supporting communication infrastructure and an IT-friendly national policy framework. They suggested that authorities adopt supportive policies that can ensure that rural populations acquire the necessary ICTrelated skills.

In the case of rural India, an e-health initiative helped reduce infant mortality rates. Venkatesh et al. [12] noted the high infant mortality rates in rural India, with over 50 deaths for every 1,000 live births, which was due to the low quality of healthcare services. They believed that ICT could serve as a tool for health-related information gathering, especially for dissemination to pregnant women and mothers. They were able to demonstrate that by using e-health kiosks for health information dissemination, infant mortality rates could be reduced by a significant percentage; however, they acknowledge the need to continue using 
pre-existing social networks and word of mouth information-sharing in geographically remote areas, with low computer literacy rates and high illiteracy.

Martinez et al. [13] also found that successful implementation of e-health in rural India was more difficult than in urban areas, due to the high cost of ICT infrastructure and low literacy rates. Nevertheless, they advocated for e-health as a means of obtaining effective healthcare, because of its power to virtually connect patients in remote areas with competent healthcare providers; however, they emphasized that authorities must consider the local needs, norms, and cultural, educational and societal factors of the targeted population, while creating a national healthcare program targeting rural areas.

Gajanayake et al. [14] examined large and small countries in the European Union (EU), noting that they had either implemented or started implementing e-health programs, to ensure universal health coverage for their populations. Although most were successful in reaching their goals, the larger countries with diverse populations like England, France and Germany, were faced with challenges due to demographic complexities. The authors used global cases to evaluate and provide recommendations for future e-health initiatives. They conclude that well-articulated plans and preparations do not necessarily guarantee success. Variables like the changing socio-political climate, social interactions, national policies and the nature of funding could affect successful outcomes. They suggested that e-health programs be based on learned experiences of self and others, relating to both successful and failed initiatives.

The United Kingdom (UK) started its e-health program in 2002, under the National Health Services (NHS), for diagnosis, information sharing, telemedicine, managing appointments online, electronic prescriptions, and providing Summary Care Records (SCRs) to both patients and healthcare providers [15]. Gajanayake et al. [14] found that initially, the program was fraught with problems. The information-gathering system was not consistent with how clinicians collect patient information and led to low rates of adoption. Furthermore, the public awareness and education campaigns about it were inadequate and resulted in a very expensive, underutilized program. Subsequently, the SCR system was modified to align with the needs of the doctors and clinicians and the e-health education campaigns were improved, so that the public became aware of the myriad benefits of participating in e-health programs. Today, the UK SCR system is used by $98 \%$ of its healthcare practitioners [16] and is heralded as a success story.

Khan et al. [17] studied Australia's My Health Record (MyHR), a fully digitized healthcare program, by examining the design of the overall system, its performance, and successes and failure points; and found that healthcare providers were slow to adopt the system, as they failed to recognize the personal benefits of the MyHR system to providers. The usability of the system for multiple users, including doctors, pharmacists, insurance providers etc., had not been highlighted enough during program implementation. Furthermore, the awareness campaigns were not well thought out and did not reach enough healthcare providers and users, which led to a high resistance to change from the traditional methods to this new system. The authors also noted that the MyHR system raised issues about the morality of accessed data for secondary use/research and uncertainty related to the legal framework within which MyHR was operating.

The above country-specific studies, although limited, are useful in expanding our understanding of the various challenges faced in rural and urban contexts. These include: a large uneducated population with low computer literacy; the digital divide in rural versus urban settings, due to lack of a robust ICT infrastructure and training program; lack of buyin from the public and associated healthcare providers; poorly designed educational campaigns that failed to communicate the value of e-health strategies for the greater good; sociocultural and financial challenges; and limiting national policies or inadequate legal 
frameworks for data sharing and privacy protection. This is further elucidated under the eight themes used by the WHO for monitoring e-health initiatives in participating countries in Table 1.

Table 1: E-health strategies across eight themes. Achievements (Yes) and challenges (No) for three countries.

\begin{tabular}{lccc}
\hline Country & $\begin{array}{c}\text { United } \\
\text { Kingdom }\end{array}$ & Australia & $\begin{array}{c}\text { South } \\
\text { Africa }\end{array}$ \\
\hline Population in millions & 63 & 23 & 53 \\
Internet users (\% population) & 87 & 82 & 41 \\
ICT Development Index rank & 8 th & 11 th & 84 th \\
1. E-health foundations & & & \\
$\begin{array}{l}\text { National universal health coverage policy or } \\
\text { strategy; }\end{array}$ & Yes & Yes & Yes \\
$\begin{array}{l}\text { National e-health policy or strategy; } \\
\text { Government supports internet sites in multiple }\end{array}$ & Yes & Yes & No \\
languages & & Yes & No
\end{tabular}

\section{Legal frameworks for e-health}

Protects the privacy of individuals' health-related data held in electronic format in an EHR;

Allows individuals electronic access to their own health-related data when held in an EHR

$\begin{array}{lll}\text { Yes } & \text { Yes } & \text { No } \\ \text { Yes } & \text { Yes } & \text { No }\end{array}$

\section{Telehealth programs}

Teleradiology, telepsychiatry

Local National No

\section{Electronic Health Records (EHR)}

National EHR system and legislation governing the use;

ICT-assisted functions like billing

$\begin{array}{lll}\text { Yes } & \text { Yes } & \text { No } \\ \text { Yes } & \text { Yes } & \text { No }\end{array}$

\section{Use of e-learning in health sciences}

Health sciences students pre-service; Health professional in-service

$\begin{array}{lll}\text { Yes } & \text { Yes } & \text { N/A } \\ \text { Yes } & \text { Yes } & \text { N/A }\end{array}$

\section{M-health (health access through mobile phone)}

Toll-free emergency;

Management of disasters and emergencies

$\begin{array}{lcc}\text { National } & \text { National } & - \\ \text { National } & - & -\end{array}$

\section{Social media}

National policy or strategy on the use of social media by government organizations

Yes $\quad$ Yes No

\section{Big data}

Governing the use of big data in the health sector; Governing the use of big data by private companies

Yes

No

Yes

No

Yes

No 
2.2 A conceptual framework for monitoring e-health initiatives

In 2015, the third Global Survey on e-health helped the creation of very informative Atlas of eHealth Country Profiles [1], with data from 125 member countries (note that KSA did not participate in this survey). Data are grouped under eight themes shown in Fig. 1.

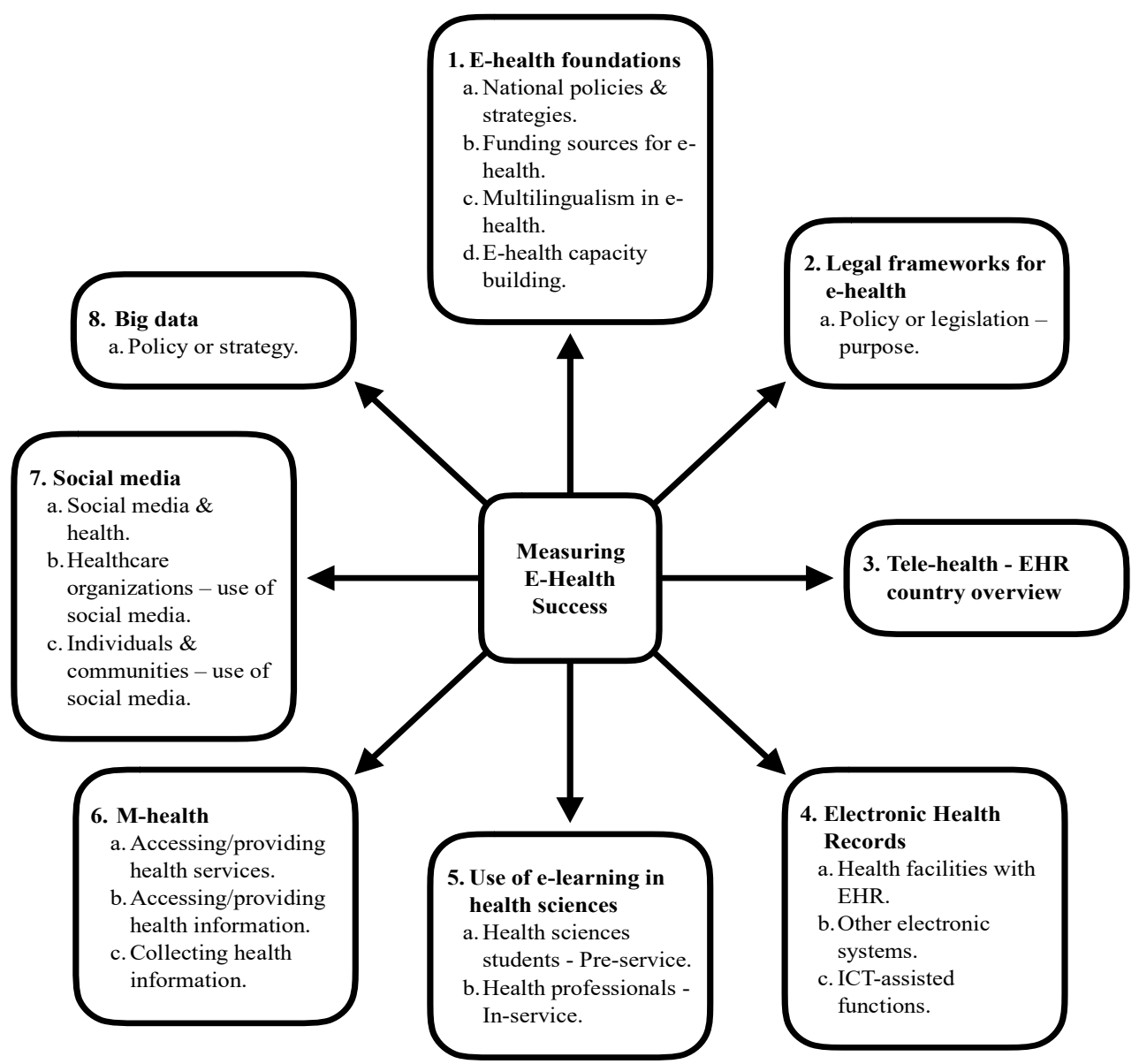

Figure 1: Conceptual framework based on WHO's highlighted themes. (Source: Adapted from the Atlas of eHealth Country Profiles, WHO [1].) Notes: E-health = electronic health, her = Electronic Health Records, ICT = information communication technology, M-health = mobile phone health.

The Atlas [1] reports on the unique progress made by the participating countries under each theme and is useful as a conceptual framework, to outline key areas of focus for our case study of the KSA. This conceptual framework is used to scan and present a truncated list of initiatives for the three countries discussed in the literature review. It serves to demonstrate the efficacy in using it for our case study analysis, in the subsequent section. 


\section{CASE STUDY}

\subsection{The context: Kingdom of Saudi Arabia}

The KSA, with a land area of 2,149,690 $\mathrm{km}^{2}$ (about $830,000 \mathrm{mi}^{2}$ ), is the largest country in the Middle East by land mass and the 14th largest in the world. A majority of the country is characterized by having a desert climate, with extreme heat during the day averaging at $45^{\circ} \mathrm{C}$ $\left(113^{\circ} \mathrm{F}\right)$ to a sudden drop in temperature at night. Some regions, like the northern historic city of Al Turaif, also experience extreme climatic variations (with lows of $-12^{\circ} \mathrm{C} / 10.4^{\circ} \mathrm{F}$, to highs of $54^{\circ} \mathrm{C} / 129.2^{\circ} \mathrm{F}$ ) [18], [19].

The roots of the country can be traced back through a long and vivid history, as both an ancient trading center and the birthplace of Islam in the early 7 th century. The Saudis are religious, traditional and family-oriented, with a majority of citizens having Bedouin descent (a nomadic Arab of the desert), who herded domestic animals: mainly sheep, goats and camels [20]. After the urbanization of the country in the early $1970 \mathrm{~s}$, more than $95 \%$ of the Bedouins settled in villages or urban areas, moving away from traditional tribal lifestyles [21] to a more service-oriented livelihood.

Shortly after the establishment of the modern state in 1932 by King Abdulaziz Al-Saud, vast amounts of oil reserves were discovered, which led to the kingdom's transformation into a rich, developed, geopolitically influential country [22]. The World Bank characterizes the KSA as a high-income economy with a very high Human Development Index (HDI) of 0.853 [30]. This positions the KSA as 39th out of the 189 countries and territories of the world. The KSA increased its HDI points by $22.1 \%$ from 1997 to 2017, due to significant progress in the economic, education and healthcare sectors. This has raised life expectancy from birth, expected years of schooling, and the gross national income per capita [23], which are key indicators for measuring human development.

Saudi Arabia's population transformed from being $74.1 \%$ rural in 1955 to being an $82.1 \%$ urbanized population by 2019 [24], [25]. The number of cities increased from 58 in 1936 to 285 in 2015; and the KSA is expected to reach a $97.6 \%$ rate of urbanization by 2030 . This urban population is predominantly settled in the five major cities of Riyadh, Jeddah, Makkah, Madina and Dammam [24]. The KSA holds a predominant position in the Arab world, as it is home to the holy cities of Makkah and Madina (Mecca and Medina), and is the global custodian of two of the most revered Islamic mosques. Every year, over 1.85 million international visitors from over 140 countries travel to the KSA to perform the Hajj pilgrimage or the Umrah [26], [27]. This requires the country's health care sector to be ever vigilant, and capable of providing affordable healthcare services to religious tourists or pilgrims, without disruptions to the domestic operations and services to its citizens and to expatriate workers.

The subject of offering e-health was heavily debated in the country during the 2000s, when scholars studying the healthcare system in the KSA found it to be lacking due to a shortage of funds, inexperienced staff, an inadequate number of facilities and increasing demand for free services. Despite a huge expenditure of SR 4 billion (Saudi Rials worth about US\$ 1.1 billion) from 2008 to 2011 for various ad hoc e-health programs, the quality of healthcare delivery was found to be unsatisfactory, due to poor coordination among healthcare service providers. This highlights a need to launch a comprehensive national healthcare system [28], enabled with ICTs.

The seeds for developing a universal e-health strategy were introduced in 2002: A recommended expansion of tele-health usage and improvements to the Electronic Health Records (EHR) systems, as well as the establishment of the health informatics society, 
colleges and research centers [29]. In 2004, the King Saud Bin Abdul Aziz University for Health Sciences (KSAU-HS) was established; and in 2005, the Saudi Association for Health Informatics (SAHI). Subsequently, several e-health conferences were organized between 2006 to 2010, to raise e-health awareness in the country and to bring in experts from around the world. These activities led to launching of the Electronic Health Center of Research Excellence (E-CoRE), to conduct e-health research that helps enhance quality and reduce costs [29].

\subsection{E-health evolution in the KSA and analysis of advancements}

Although the KSA did not participate in the 2015 third Global eHealth Survey by the WHO, we found merit in using the eight themes used therein to analyze the advancements that have been made in e-health and outline any key areas of focus for the KSA (Fig. 1). It also will serve as a guide for future research and policy-making, possibly focused on Smart e-health Village enterprises.

\subsubsection{Theme 1: E-health foundations}

In the KSA, our e-health foundations pertain to national policies and strategies, funding sources for e-health enterprises, multilingualism in e-health, and capacity-building initiatives. In 2011, the Saudi Ministry of Health (MOH) launched a national e-health program, and it continues to earmark millions in funding to ensure that the program reaches world-class standards. The aim is to offer digitally equipped universal health coverage to all KSA residents, through government and private sector healthcare providers, to enhance efficiency, transparency and equity [30]. This will improve access to limitless data and promote cost savings [31], [32], by reducing the volume of revisits to healthcare clinicians. There are plans to continue to promote the use of multiple e-tools, including internet sites, SMS texting, telephone and digital information [33]-[35], to enhance e-health adoption; however, Saudi national policies and strategies for universal health appear to fall short of addressing the unique needs of rural populations, multilingual expatriate and religious tourist populations, and diversification of funding for e-health initiatives. Currently, funding is provided only by the government sector $(\mathrm{MOH})$, which is clearly inadequate and unsustainable, as demand for health services multiplies. Investments by private or commercial, and non-profit health care sectors should be pursued, targeting rural needs. Furthermore, over $30 \%$ of the KSA expatriate population (10.7 million) [43], and thousands of international religious tourists, do not speak Arabic nor English. This underscores the need for national policies and legal frameworks for multilingualism in e-health.

The government should also support internet sites carrying health data in multiple languages, similar to the US Centers for Disease Control and Prevention (CDC). Also, there is an urgent need to build workforce capacity of ICT-trained staff, including physicians, clinicians, and ICT specialists, for healthcare enterprises [40]. This can be done by instituting a national training and recruitment strategy and encouraging rural youth to join the health sector enterprise as a career choice, through additional scholarships.

\subsubsection{Theme 2: Legal frameworks for e-health}

Legal frameworks for our eHealth Program pertain to policy or legislation, tele-health, EHRs, health facilities with EHR and ICT-assisted functions. In KSA, current legal frameworks are limited to patient privacy and information accessibility [44]. The present-day digital environment is complex, and the legal frameworks governing the sharing of health 


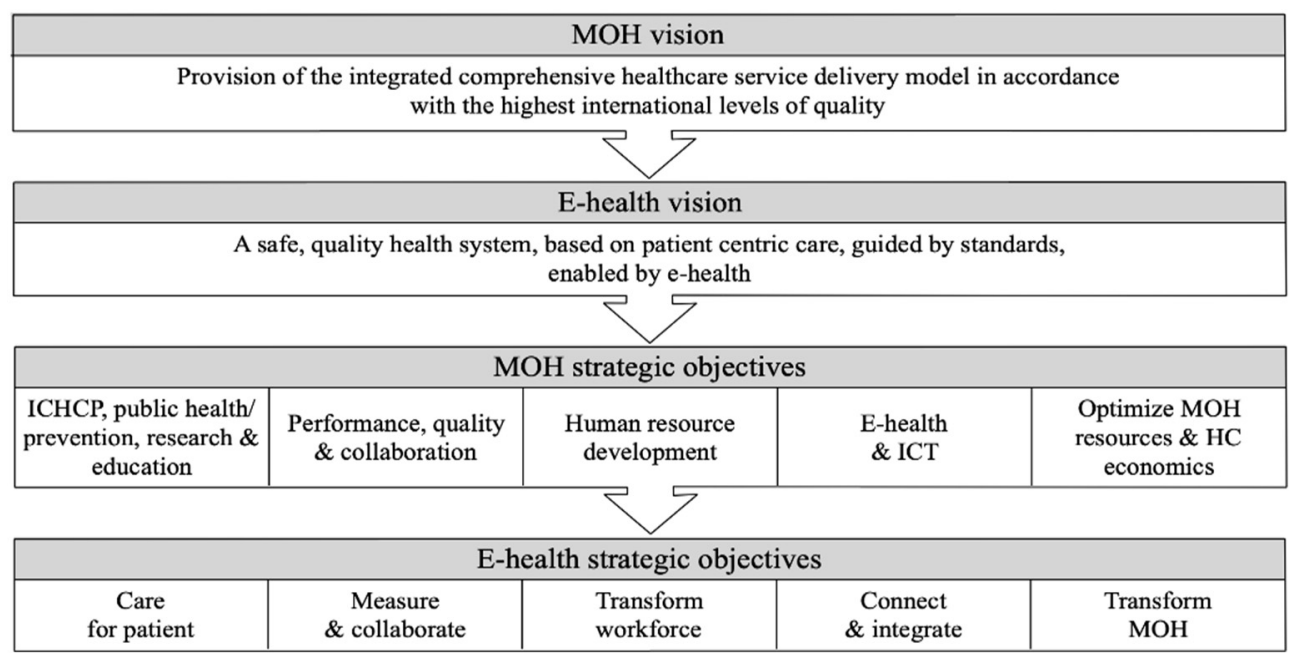

Figure 2: $\mathrm{MOH}$ strategic objectives focused on e-health and ICT [9, p. 270]. Notes: HC = healthcare, ICHCP $=$ Integrated and Comprehensive Healthcare Plan, ICT $=$ information communication technology, $\mathrm{MOH}=$ Saudi Ministry of Health.

information with professionals and researchers in other health organizations both within KSA and internationally need to be expanded upon (Fig. 2).

\subsubsection{Theme 3: Tele-health EHR}

Of all the common tele-health programs, only tele-radiology and remote patient monitoring have received mention at the national level, in the Saudi Health Information Exchange (HIE) platform [33]. With regard to remote patient monitoring, encouraging smart cities to adopt adjoining or nearby villages may offer solutions to facilitate remote patient monitoring and create hubs and sub-hubs of monitoring stations, so as to replicate and transfer the implementation of high-quality services to rural areas [45].

\subsubsection{Theme 4: Electronic Health Records (EHRs)}

EHRs include health care facilities that have adopted EHR and ICT enabled functions. Although there is a nationally governed interoperable Electronic Health Record (iEHR) system in the KSA, designed to offer unified, simple, user friendly and patient-centric services to help hospitals and emergency care units, most of its functions continue to be under-utilized [41]. Constantly updating the e-health system with advanced technologies is costly. Furthermore, having a growing aging population with a higher percentage with chronic diseases [36] is a challenge. The adoption and efficacy of the iEHR system can be increased by improving the integration with smaller primary health care facilities and offering incentives such as discounts to providers and patients, or even making it mandatory, as has been done in other developed nations (e.g. UK).

Research in health promotion and communication have consistently highlighted how "planned, persuasive messaging and communication campaigns can change awareness and health behaviors within populations" [37, p. 39]. Although the $\mathrm{MOH}$ focuses on chronic diseases like hypertension, diabetes, obesity and recent contagious diseases and viruses like MERS-Corona, Zika and Ebola viruses, it also raises awareness to lesser-known diseases like 
cholera, meningitis, yellow fever, Rift Valley fever, and dengue fever [33]. The MOH initiated a nationwide health awareness initiative campaign in 2016, using printed materials, fixed and mobile public displays, electronic message screens; and basic health care supplies like filter masks, hand sanitizer and umbrellas. They used text messages, cell phone banners, social media messaging, public service announcements (radio and TV), and flyers at special events including the Your Health in Hajj and Umrah booklets. These efforts are commendable and will continue to highlight the importance of e-health strategies and adoption of iEHR.

\subsubsection{Theme 5: Use of e-learning in health sciences}

Use of e-learning in health sciences pertains to pre-service students registered in health science degree-granting institutions and in-service health professionals. In this regard, the Saudi Association for Health Information (SAHI) uses e-learning to benefit health sciences students to access online training, which is convenient for rural practitioners [46]; however, little information is available on how local health entities are facilitating e-learning techniques for training their own employees. Investments should be made to ensure that inservice health professionals are offered continuing credits for training, to update their ICT skills to ensure computer literacy, which is the backbone of KSA e-health enterprises.

\subsubsection{Theme 6: M-health}

M-health pertains to accessing or providing health services and collecting, accessing and providing health information using one's mobile phone. Success with M-health is growing in KSA since the mobile penetration rate and internet users have reached about $100 \%$ in 2018, according to the General Authority for Statistics (GASTAT), while the total number of mobile phone users has reached 99.16\% [18], [47]. According to the Arab News [48], the $\mathrm{MOH}$ introduced a toll-free health call center to provide medical counselling, internal referrals, and health-related information to the whole Saudi population. It was designed to increase awareness about infectious diseases, toxins and medicines. The center also collects complaints and suggestions from public and private health facilities; and evaluates, displays and updates statistics on the current level of delivered services.

\subsubsection{Theme 7: Social media}

The Social Media theme includes the use of social media channels for communicating health information by healthcare organizations, individuals and communities. In KSA, social media platforms, mainly Twitter and Rich Site Summary (RSS), are frequently used by national officials and ministries [49]. Moreover, via this platform, most health services are utilized by patients and care providers [33], [50]. The MOH governs this new communication tool by putting forward a specific national social media strategy on its official website [33]. The $\mathrm{MOH}$ has also engaged various stakeholders to manage resistance to e-health adoption and to guarantee effective implementation [9], [33]. In an attempt to transform the Saudi healthcare system through the National Transformation Program (NTP) 2020 and Vision 2030, the $\mathrm{MOH}$ started more than 40 health initiatives, including persuasive health communication messaging and e-health. Its vision is "a safe, quality health system, based on patient centric care, guided by standards, enabled by e-health" [9, p. 4].

In 2018, the MOH introduced "Seha", a mobile app used to deliver 1.4 million virtual health consultations in that year alone, which resulted in reduced doctor wait times and human-related errors. The ministry also created the "Mawid" app, to book patient appointments; as well as the medical staff-focused "Ashanak" and "Mawared" apps. Services manage registration, diagnoses and follow-ups [33]. This allows accessing of patient's 
information with ease and provides services remotely [38]. These digital capabilities are part of the MOH's framework (Fig. 2). The rate of use and challenges needs to be monitored and measured through future research initiatives.

\subsubsection{Theme 8: Big data}

The big data theme pertains to the policy or strategy for collecting and managing large volumes of data collected by the integration of various digital resources. There is not sufficient information openly available in this regard in KSA, but must include rural and urban needs utilization of big data technologies.

\section{DISCUSSION AND CONCLUSIONS}

This paper presents the evolution of e-health strategy in the KSA, using WHO's eight themes for examining advancements made in e-health adoption in countries. We acknowledge that others have also studied various aspects of e-health adoption in KSA but were rather ad hoc; a more systematic review was needed.

For example, Jamal et al. [39] focused on Saudi patients' health information-seeking behaviour, as well as the quality of online sources and patient usage. These results indicate that the internet provides valuable health information that positively impacting healthcare outcomes. The authors conclude that patients who search for health-related information online are more aware and take preventive measures to enhance their quality of life than others. Patients considered online sources as secondary to physicians and television announcements.

Alsulame et al. [40] investigated KSA's e-health system from the perspective of nine senior health information professionals, in 2013. Their findings suggest that e-health adoption varied among participants and their organizations. Challenges also stem from organizational and cultural reasons, end-user's perspectives of risks, and lack of qualified personnel to use the e-health system. Study participants recommended an independent national e-health entity that provides a central plan for implementing the initiative.

El Mahalli [41] focused on physicians' use of Saudi electronic health records (EHR) by conducting a cross-sectional study with 555 physicians from three public hospitals in the Eastern Province of the country. Services scrutinized included data back-up/ICT disaster recovery, pharmacy orders, customer contact and accessing health records. Their results show that most e-health functions are under-utilized, due to system hang-up, computer crash, power failure and excessive data entry.

These studies and ours lead us to conclude that if the KSA wants to make advancements in universal health coverage and reach an enviable position in e-health adoption compared to other developed nations of the world, it needs to focus its attention and investments on reducing the gaps between the urban and rural populations. The challenges and solutions to advancing e-health reaching into the $17 \%$ rural communities are listed in Table 2.

Furthermore, the $\mathrm{MOH}$ and researchers in the field of public administration, healthcare, medicine and social sciences could use the Atlas of eHealth Country Profiles by the WHO to guide information-gathering for future research in rural contexts, to reduce the divide. The country may also consider conducting a self-evaluation across all eight themes and participate in the survey in the future. Investments in the implementation of Smart eHealth Village enterprises should receive precedence. Local health officials facilitating forums and workshops about the use of this program can increase the successful implementation, as they are the authentic "known" local providers. 
Table 2: Challenges and solutions for increasing e-health strategies in rural communities. ICT: information communication technology, MOH: Saudi Arabia's Ministry of Health, TV: television.

\section{Challenges amplified in rural communities \\ 1. Care of patient \\ - People still prefer physicians and the TV as methods to receive health-related information; the Internet is only a secondary source [39]. \\ - Most of the e-health functions were under-utilized [41]. \\ - Patients unaware of the importance of e-health initiatives and how to access it [5], [9]. \\ - Poor accessibility to healthcare services and facilities continues [3], [28].}

\section{Measure and collaborate}

- Shortage of services expressed by patients, due to high demand for free services [28].

- Poor coordination among healthcare service providers [28].

\section{Transform workforce}

- There is continued lack of healthcare funding [28].

- There is continued lack of qualified personnel in the ehealth systems [40].

\section{Connect and integrate}

- Recurring system hang ups, computer crashes, power failures and long data entry times [41].

\section{Transform MOH}

- Large geographical area with numerous rural villages [42] need new policies.

- Planning needs to be more developed, based on individual characteristics [5], i.e. culture-centric policies and efforts.

- Steady long-term funds must be allocated for national ehealth applications [5].

\section{Solutions}

- Need patient care orientation

- Change messaging and communication to rural-centric

- Invest in rural ICT infrastructure

- Encourage crosstraining and coordination

- Focus on better workforce orientation through training and ICT literacy

- Ensure ICT standardization

- Introduce rural-centric legal frameworks and policies

- Disburse rural healthcare funds over a longer term and monitor progress

In conclusion, the MOH e-health initiatives can overcome limitations in our traditional healthcare systems with additional efforts by a coalition of KSA government, and private and non-profit sector stakeholders. This must be designed based on the nation's population, healthcare needs, economy and national legal frameworks.

\section{REFERENCES}

[1] World Health Organization, eHealth conversations: using information management, dialogue, and knowledge exchange to move toward universal access to health. http://iris.paho.org/xmlui/bitstream/handle/123456789/28392/9789275118283_eng.p df? sequence=1\&amp;isAllowed=y. Accessed on: 11 Sep. 2019.

[2] Al Shorbaji, N., E-health in the Eastern Mediterranean Region: A decade of challenges and achievements. Eastern Mediterranean Health Journal, 14, pp. 157-173, 2008. 
[3] Agrawal, A. et al., Integrating health care delivery and data collection in rural India using a rapidly deployable e-health center. PLoS Medicine, 10(6), e1001468, 2013.

[4] Currie, M., Philip, L.J. \& Roberts, A., Attitudes towards the use and acceptance of ehealth technologies: A case study of older adults living with chronic pain and implications for rural healthcare. BMC Health Services Research, 15(1), p. 162, 2015.

[5] Chesser, A., Burke, A., Reyes, J. \& Rohrberg, T., Navigating the digital divide: A systematic review of e-health literacy in underserved populations in the United States. Informatics for Health and Social Care, 41(1), pp. 1-19, 2016.

[6] Shukla, P.Y., The Indian smart village: Foundation for growing India. International Journal of Applied Research, 2(3), pp. 72-74, 2016.

[7] Malche, T. \& Maheshwary, P., Internet of Things (IoT)-based water level monitoring system for smart village. Proceedings of International Conference on Communication and Networks, Springer: Singapore, pp. 305-312, 2017.

[8] United Nations Development Programme, About Saudi Arabia. www.sa.undp.org/ content/saudi_arabia/en/home/countryinfo.html. Accessed on: 5 Sep. 2019.

[9] Balkhair, A., Kingdom of Saudi Arabia, The National e-Health Program, 2012. www.itu.int/ITU-D/cyb/events/2012/e-health/Nat_eH_Dev/Session\%204/KSAMOH-Presentation-SaudiArabia\%20FINAL.pdf. Accessed on: 7 Sep. 2019.

[10] Al-Nozha, M.M. et al., Diabetes mellitus in Saudi Arabia. Saudi Medical Journal, 25(11), pp. 1603-1610, 2004.

[11] Ruxwana, N.L., Herselman, M.E. \& Conradie, D.P., ICT applications as e-health solutions in rural healthcare in the Eastern Cape Province of South Africa. Health Information Management Journal, 39(1), pp. 17-29, 2010.

[12] Venkatesh, V., Rai, A., Sykes, T.A. \& Aljafari, R., Combating infant mortality in rural India: Evidence from a field study of e-health kiosk implementations. Mis Quarterly, 40(2), pp. 353-380, 2016.

[13] Martinez, S., Gerdes, M., Kumar, S., Kumar, A., Gill, S. \& Loudon, G., eHealth activists: The lifeline for remote rural villages in India, University of Agder, 2018. https://repository.cardiffmet.ac.uk/bitstream/handle/10369/9670/RethinkingRemote V0_20180516.pdf? sequence $=1$.

[14] Gajanayake, R., Sahama, T. \& Iannella, R., E-health in Australia and elsewhere: A comparison and lessons for the near future. HIC, pp. 26-32, 2013.

[15] Jones, V. \& Jollie, C., eHealth strategy and implementation activities in England. Report on the framework of the eHealth European Research Area (ERA) project, 2007.

[16] UK National Health Service, Summary Care Records. https://digital.nhs.uk/services/ summary-care-records-scr. Accessed on: 5 Sep. 2019.

[17] Khan, U.R., Zia, T.A., Pearce, C. \& Perera, K., The My Health Record (MyHR) adoption in general practices: Literature review and future research direction. The International Technology Management Review, 7(1), pp. 81-92, 2018.

[18] General Authority for Statistics: Kingdom of Saudi Arabia. www.stats.gov.sa/en/4025. Accessed on: 5 Sep. 2019.

[19] Weather Online, Saudi Arabia. www.weatheronline.co.uk/reports/climate/SaudiArabia.htm. Accessed on: 11 Sep. 2019.

[20] Tripp, H. \& North, P., Culture Shock!: Saudi Arabia, Graphic Arts Center Publishing Company, 2003.

[21] House, K.E., On Saudi Arabia: Its People, Past, Religion, Fault Lines and Future, Vintage, 2013.

[22] United Nations Development Programme, About Saudi Arabia. www.sa.undp.org/ content/saudi_arabia/en/home/countryinfo.html. Accessed on: 5 Sep. 2019. 
[23] United Nations Development Programme, Human development indices and indicators: 2018 statistical update briefing note for countries on the 2018 statistical update. Saudi Arabia, 2018. http://hdr.undp.org/sites/all/themes/hdr_theme/country-notes/SAU.pdf. Accessed on: 8 Sep. 2019.

[24] United Nations Habitat, Saudi Arabia: Urban issues. https://unhabitat.org/saudiarabia-urban-issues/. Accessed on: 5 Sep. 2019.

[25] Worldometers, Saudi Arabia population. www.worldometers.info/world-population/ saudi-arabia-population/. Accessed on: 5 Sep. 2019.

[26] Ministry of Hajj and Umrah. www.haj.gov.sa/en. Accessed on: 11 Sep. 2019.

[27] Taibah, H., Arlikatti, S. \& Andrew, S., Risk communication for religious crowds: Preferences of Hajj pilgrims. Disaster Prevention and Management, 27(1), pp. 102$114,2018$.

[28] Almalki, M., FitzGerald, G. \& Clark, M., Health care system in Saudi Arabia: An overview. Eastern Mediterranean Health Journal, 17(10), pp. 784-793, 2011.

[29] Househ, M., Al-Tuwaijri, M. \& Al-Dosari, B., Establishing an Electronic Health Center of Research Excellence (E-CoRE) within the Kingdom of Saudi Arabia. Journal of Health Informatics in Developing Countries, 4(1), 2010.

[30] Vision 2030. https://vision2030.gov.sa. Accessed on: 8 Sep. 2019.

[31] Atallah, N., Khalifa, M., El Metwally, A. \& Househ, M., The prevalence and usage of mobile health applications among mental health patients in Saudi Arabia. Computer Methods and Programs in Biomedicine, 156, pp. 163-168, 2018.

[32] Meskó, B., Drobni, Z., Bényei, É., Gergely, B. \& Győrffy, Z., Digital health is a cultural transformation of traditional healthcare. Mhealth, 3, 2017.

[33] Saudi Arabia Ministry of Health, Ministry of Health apps for smartphones. www.moh.gov.sa/en/Support/Pages/MobileApp.aspx. Accessed on: 11 Sep. 2019.

[34] Taibah, H., Arlikatti, S. \& Andrew, S., Risk communication for religious crowds: Preferences of Hajj pilgrims. Disaster Prevention and Management, 27(1), pp. 102114, 2018.

[35] Taibah, H. \& Arlikatti, S., An examination of evolving crowd management strategies at pilgrimage sites: A case study of "Hajj" in Saudi Arabia. International Journal of Mass Emergencies and Disasters, 33(2), 2015.

[36] Al-Hanawi, M.K., The healthcare system in Saudi Arabia: How can we best move forward with funding to protect equitable and accessible care for all. Int. J. Healthcare, 3(2), pp. 78-94, 2017.

[37] Glik, D.C., Risk communication for public health emergencies. Annual Review Public Health, 28, pp. 33-54, 2007.

[38] Paules Ciprés, A., Fardoun, H.M., Alghazzawi, D.M. \& Oadah, M., KAU e-health mobile system. Proceedings of the 13th International Conference on Interacción Persona-Ordenador, p. 29, ACM, 2012.

[39] Jamal, A. et al., Association of online health information-seeking behavior and selfcare activities among type 2 diabetic patients in Saudi Arabia. Journal of Medical Internet Research, 17(8), e196, 2015.

[40] Alsulame, K., Khalifa, M. \& Househ, M.S., E-health in Saudi Arabia: Current trends, challenges and recommendations. ICIMTH, 213, pp. 233-236, 2015.

[41] El Mahalli, A.A., Electronic health records: Use and barriers among physicians in eastern province of Saudi Arabia. Saudi Journal for Health Sciences, 4(1), p. 32, 2015.

[42] Alharbi, F., Atkins, A. \& Stanier, C., Strategic framework for cloud computing decision-making in healthcare sector in Saudi Arabia. 7th International Conference on e-Health, Telemedicine, and Social Medicine, 1, pp. 138-144, 2015. 
[43] Global Media Insight, Saudi Arabia's population statistics of 2019. www.globalmediainsight.com/blog/saudi-arabia-population-statistics/\#expats). Accessed on: 11 Sep. 2019.

[44] STC, Digital policy, His Excellency Mohamed Jamil Mulla: on supporting the fast pace of change in KSA, 2011. www.stc.com.sa/wps/wcm/connect/english/stc/ resources/9/5/95436188-67ab-4775-9db9-a94d7a1066d8/Digital_Policy_Issue_1_ English.pdf?attachment=true\&id=1339223519074. Accessed on: 5 Sep. 2019.

[45] English Alarabiya, Why smart cities should create "smart villages" too. http://english.alarabiya.net/en/views/news/middle-east/2016/02/13/Smart-cities-andsmarter-villages.html. Accessed on: 11 Sep. 2019.

[46] The Saudi Association for Health Information, What is health informatics? www.sahi.org.sa/?page_id=2375. Accessed on: 22 Sep. 2019.

[47] Zawya, Mobile, internet penetration nears $100 \%$ in 2018 in Saudi Arabia. www.zawya.com/mena/en/business/story/Mobile_internet_penetration_nears_100_in 2018_in_Saudi_Arabia-ZAWYA20190102050230/. Accessed on: 5 Sep. 2019.

[48] A Arab News, Saudi Health minister opens new emergency call center, 2017. www.arabnews.com/node/1073661/saudi-arabia. Accessed on: 18 Sep. 2019.

[49] Al-Badi, A.H., The adoption of social media in government agencies: Gulf Cooperation Council case study. Journal of Technology Research, 5, p. 1, 2014.

[50] Giustini, D., Ali, S.M., Fraser, M. \& Boulos, M.N.K., Effective uses of social media in public health and medicine: A systematic review of systematic reviews. Online Journal of Public Health Informatics, 10(2), 2018. 